council members to transform the CNR into "a great laboratory of war and peace". Soon after taking office, however, Marconi moved on to even more spectacular scientific adventures, leaving the CNR in the hands of the vice-president, a fascist bureaucrat. From 1937, and during the war, General Pietro Badoglio, a powerful military and political figure, became CNR president, with a mandate to promote war-orientated science and technology.

It is interesting that the Italian scientific community mostly ignored Badoglio's loud propaganda, and very little science for war was developed - unlike the situations in Britain and Germany. Mussolini did not trust university professors much, despising their inclination to pursue fundamental research and ignore industrial applications. With these unresolved contradictions, the CNR entered the war period.

This early story is documented in detail with fascinating extracts from correspondence between scientists, politicians and members of the CNR council. When read decades later, comments, opinions and gossip reveal much more about the political planning behind the scene than do the official facts - as well as revealing the personalities of the correspondents, all outstanding figures in Italian science.

For example, in 1936, Giulio Cesare Trabacchi, director of the Istituto Superiore di Sanitá (National Institute of Health), lost 10,000 lire (a significant amount of money at the time) from his CNR grant after a clerk mistakenly assigned it to Enrico Fermi, who was then still working in Italy. Responding to a letter in which it was suggested that the sum could be returned to him and stripped from Fermi's grant the following year, he replied: "I have closely followed Fermi and his school's work and I well know how desperately meagre are the resources available to them. I would accept the proposition you suggest only if I could be sure my work could be compared to Fermi's and collaborators': I know this can't be done ... I therefore will continue with the ordinary grant I so far had access to." It is now clear why Trabacchi is the only person Fermi thanked in his Nobel lecture after winning the prize for physics in 1938.

The second of these volumes spans the period from the post-war republic to the present. It is inevitably written almost as a chronicle, and touches on delicate points concerning people who are still alive and active in their fields. The change in style between the volumes prompts a general question: how will future historians assess our present era of non-archived web documents, e-mails and all-too-frequent mobile phone calls? Records of who was where at what time, and of what they were thinking or working on, and with whom - the
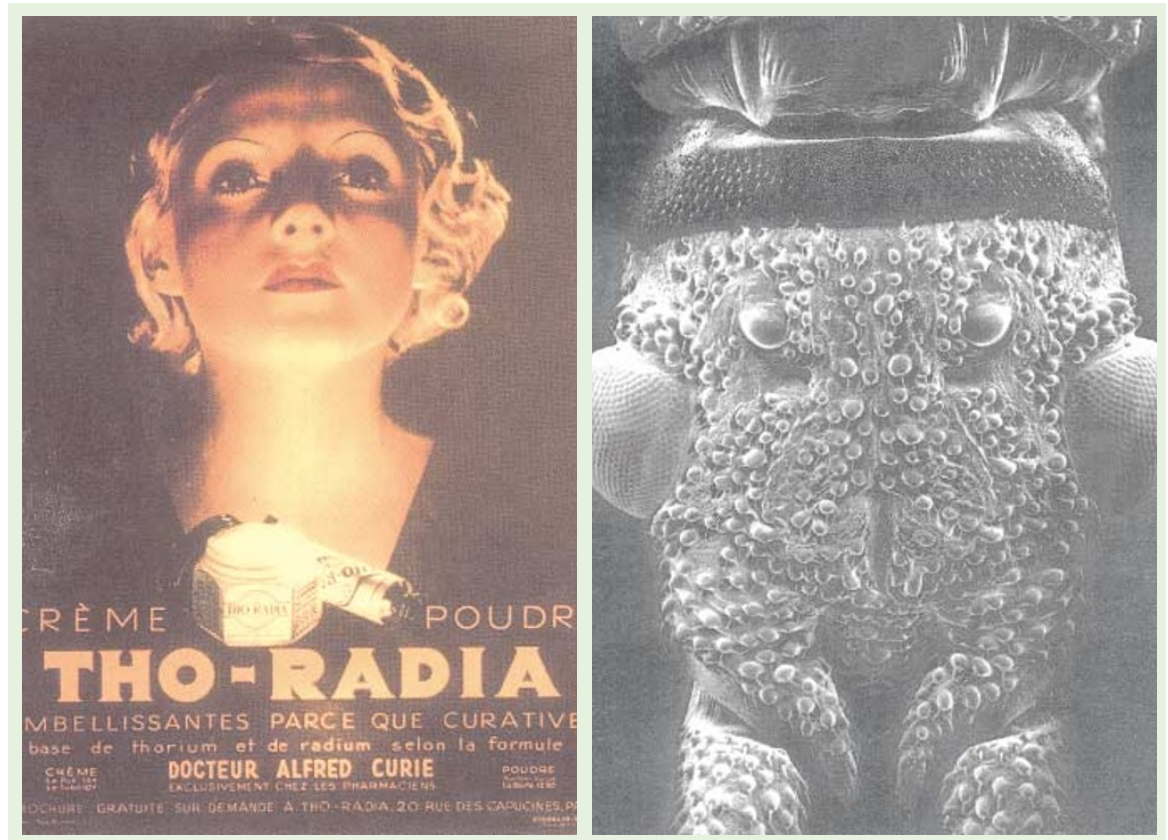

\title{
Beauty and the beast
}

Images from the Dictionnaire culturel des sciences (Editions du Regard/Editions du Seuil, 2001, FF495, in French), an eclectic mix of a thousand short articles on science and its influences on and from art, cinema, literature, politics and religion. From ADN (DNA to English speakers) to Zoroastre, this is a book to delight and provoke, in which Niels Bohr keeps company with James Bond and William Blake. 'Beauty' (left) is an advertisement for a beauty product that purported to use radium; 'beast' (right) is an artist's impression of an electron micrograph of a bed-bug, entitled 'Doctor Honoris Causa'. human aspects of history — are all bound to be lost.

The post-war years have seen the CNR's scientists promoting European collaborations (through CERN - the European Organization for Nuclear Research - and ESRO, the latter of which metamorphosed into the European Space Agency and the European Southern Observatory, among other agencies), activating connections with the United States, particularly with colleagues who had fled the fascist regime, and starting technological projects, such as a programme for science in space. However, in the account, little emerges of the intricacies of the political scene. No doubt it is too early - the books, in fact, are presented as a contribution for a history of the CNR to be written in the future.

After the war, scientific leadership resided in the universities, and most CNR laboratory directors were university professors; CNR laboratories and research centres were physically located in university buildings. In the late 1960s, however, a significant change occurred with the creation of independent institutes; CNR directors are now mostly staff members of these facilities. The price of independence from academia has been high: scientific isolation and almost no access to graduate students and postdocs.
Since the 1960s, the CNR has had a peculiar policy of recruiting in 'quantum' jumps. A few months ago, for instance, about one thousand people became staff members all at once after about ten years of 'hanging around'. But in spite of all the clumsy planning, a good deal of Italy's basic research is done within the CNR or in collaboration with CNR staff.

Present CNR leaders should take a close look at these two volumes. The political approach to science in Italy is described well, and its somewhat baroque design emerges clearly. All evolutionary efforts seem to have been in vain. For example, the most outstanding and constant feature of the CNR is its endemic lack of funds. The recurrent cry of presidents, of whatever political faith, has been that Italy's investment in science and research has been at best about half that of other developed countries, and more often only a third. As a rule, CNR scientists receive salaries, offices and lab space and not much else; research grants must be sought elsewhere. Perhaps the current restructuring will give the CNR the opportunity to finally realize Volterra's dream.

Giorgio G. C. Palumbo is in the Astronomy Department, University of Bologna, Via Ranzani 1, 40127 Bologna, Italy. 